\title{
Medición de la calidad del servicio en las instituciones financieras a través de la escala de Servqual
}

Milángela del $C$.

Morillo Moreno

Facultad de Ciencias Económicas y Sociales, Universidad de

Los Andes

morimorenca@hotmail.com

Marysela $C$.

Morillo Moreno

Facultad de Ciencias Económicas y Sociales, Universidad de Los Andes

morillom@ula.ve

Douglas E. Rivas Olivo Facultad de Ciencias Económicas y Sociales, Universidad de Los Andes

drivas@ula.ve

\section{Resumen}

La dinámica competitiva de las organizaciones, como elemento estratégico, se ha centrado en la prestación de servicios personales. En la banca son ineludibles este tipo de servicios, aun cuando muchos de ellos son a distancia (cajeros automáticos e Internet), los encuentros personales continúan vigentes con múltiples ventajas para proveedores y usuarios. Esta investigación tiene por objeto medir la calidad de los servicios personales prestados en las agencias de las instituciones financieras del municipio Libertador del estado de Mérida, Venezuela, a través de la escala de Servqual. Como resultado se obtuvo que, a pesar de que niveles globales de la calidad del servicio personal son positivos, la calidad medida por atributo presentó déficit en confiabilidad, seguridad y responsabilidad; todos de elevada importancia para los usuarios. La mayoría de deficiencias está asociada al tiempo de espera y a la actitud del personal. Igualmente, se encontró correlación entre las puntuaciones de Servqual asociadas a la confiabilidad y a la responsabilidad agrupadas en factores como tiempo de servicio, interés del empleado por el usuario y la exactitud en el servicio. Por esta razón se formularon sugerencias para la administración en cuanto a tiempos de espera, actitud y desempeño de los empleados, así como la recuperación del servicio deficiente.

Palabras claves: gerencia, calidad, servicios y Servqual. 


\title{
Service quality assessment in financial institutions using the Servqual scale
}

\begin{abstract}
Competitive dynamics of organizations is usually focused on the provision of personal services as a strategic factor. In banking, personal services are inescapable, though there are many remote services (ATM, Internet), personal meetings are still used, with multiple advantages for suppliers and users. This research is aimed at assessing the quality of personal services offered in the different financial institutions in the Libertador Municipality of the State of Merida, Venezuela, using SERVQUAL scale. The result was that while overall levels of personal service quality are positive, as measured by the quality attribute, a deficit in reliability and safety, of high importance to users together with responsibility, was observed, and most deficiencies are associated to time in wait and staff attitude. Similarly, correlation was found between the scores of Servqual associated with reliability and responsibility and grouped by factors, such as length of service, the employee's interest in users and accuracy in service, and for this reason, suggestions for managing time in wait, attitude and performance of employees as well as service recovery are offered.
\end{abstract}

Keywords: management, quality, services, Servqual.

\section{Introducción}

La calidad de los servicios se ha constituido en elemento fundamental de la oferta de muchos sectores de actividad en Venezuela. Actualmente, representa un aspecto diferenciador, un atributo indispensable para los consumidores de un servicio determinado, donde la evaluación a dicha calidad se encuentra ubicada en el plano competitivo. Por ello, a las organizaciones les corresponde comparar su desempeño con sus principales competidores aun cuando no sean proveedores de servicios sustitutivos directos debido a que los clientes comparan el servicio recibido de las diferentes organizaciones proveedoras. En este sentido, es importante que los proveedores de servicio se preocupen por gestionar la calidad si desean tener éxito, mantener o incrementar sus utilidades o simplemente sobrevivir en un medio competitivo.

La calidad en los servicios se concibe y se gestiona de manera distinta en otras actividades (industrial, agropecuaria), producto de las características distintivas definidas por Kotler y Armstrong (2003) como: intangibilidad, inseparabilidad, variabilidad y naturaleza perecedera. Sin embargo, es preciso que la calidad del 
servicio ofrecido se mida periódicamente, pues según Lovelock y Wirtz (2008) no se puede controlar lo que no se puede medir. Para Gray y Harvey (1997:163), el servicio de calidad es un espiral interminable de mejoras; para alcanzarla no basta realizar una acción determinada, sino trabajar de forma constante, eficiente e indetenible aunque se haya logrado una calidad temporal; es necesario realizar evaluaciones periódicas que arrojen información para generar estrategias de mejoramiento continuo. Por ello, es conveniente realizar mediciones periódicas de la calidad del servicio, adaptadas a la complejidad organizacional y particularmente en las instituciones financieras para diseñar estrategias en pro de la calidad.

Los servicios de las instituciones financieras juegan un papel trascendental en la sociedad moderna. De acuerdo con Cobra (2002), los servicios bancarios son complejos al combinar aspectos tangibles (pagos, retiros, depósitos, la atención amable en caja) e intangibles (sensación de seguridad, capacidad de respuesta y responsabilidad de los funcionarios). La globalización ha llevado a las instituciones financieras a ser competitivas con inversión tecnológica e innovación como estrategia de diferenciación para asegurar fidelidad del cliente. También poseen retos y cambios estructurales, puesto que la gran cantidad de competidores imposibilita la creación de productos y/o servicios diferenciadores, por lo que las innovaciones y la diferenciación tecnológica son fácilmente transferidas y superadas por la competencia. Por ello, esas instituciones deben hallar formas menos convencionales para el desarrollo y mantenimiento de sus ventajas competitivas poniendo énfasis sobre aspectos intangibles de los servicios que agregan valor a los servicios prestados. Estas instituciones deben optar por satisfacer a sus clientes mediante estrategias de calidad: "los servicios son lo único que los bancos pueden vender, son la única manera de ser diferentes" (Gray y Harvey, 1997: 71), por lo que el único elemento diferenciador es la calidad (Berry, Bennet y Brown, 1989).

En Venezuela las instituciones financieras ${ }^{1}$ juegan un papel preponderante en la economía, así lo revelan las cifras asociadas del aporte al PIB y el nivel de empleo. Según la Superintendencia de Bancos y otras Instituciones Financieras (SUDEBAN, 2007), la participación representativa del sistema bancario en los subsistemas banca universal y comercial agrupan el $62.07 \%$ de las instituciones

\footnotetext{
${ }^{1}$ En Venezuela, de acuerdo con los informes del Banco Central de Venezuela (2007) y Sudeban (2007 $)$, el sistema de las instituciones financieras agrupan a entidades bancarias denominadas banca comercial, banca hipotecaria, banca de inversión, banca universal, banca de desarrollo, bancos de leyes especiales, entidades de ahorro y préstamo, empresas de arrendamiento financiero y fondos del mercado monetario.
} 
bancarias legalmente autorizadas para funcionar en el territorio nacional. Según Gómez (2005 y 2005a), los servicios financieros en Venezuela son utilizados por una gran cantidad de clientes particulares y un importante segmento de comercios y organizaciones, y se han convertido en el dolor de cabeza para muchos de los clientes. Pese a la llegada al país de instituciones de gran trayectoria como Banco Bilbao Vizcaya, los Grupos Santander e Infisa, la mayoría de los servicios bancarios siguen manejándose desde una óptica tradicional que se aleja de los criterios de competitividad y eficiencia que reinan en el nivel mundial. Esto no sólo causa el congestionamiento de las agencias ${ }^{2}$, sino también de aquellos servicios conexos como son cajeros automáticos, taquillas externas y operadores telefónicos que no se dan abasto ante el crecimiento de una demanda de clientes que esperan recibir un mejor trato a la hora de realizar sus transacciones. Para Grasso (2006) y Gómez (2005), entre los principales problemas que afronta la banca venezolana destacan saturación del mercado; dificultad para mantener cuotas de mercado; mayor competencia; un cliente más estricto, inflexible, crítico en la selección y que demanda calidad, dado que en la mayoría de operaciones personales se generan insatisfacciones del usuario: largas esperas, inseguridad e incapacidad de respuesta. Según Datanalisis $^{3}$ (2004), en los últimos años la prestación de servicios de calidad ha cobrado importancia para los consumidores. Y aunque para Díaz (2005) y Hoffman y Bateson (2002) la banca electrónica ha revolucionado las operaciones en las instituciones financieras, aún son muchas las operaciones necesarias e imprescindibles que se llevan a cabo personalmente. Por ello, es importante enfatizar en la calidad del servicio personal en las instituciones financieras.

\section{Revisión teórica}

Según especialistas como Cantú (2006) y Hoffman y Bateson (2002), el análisis de la calidad del servicio se da por una serie de modelos conceptuales e instrumentos. Éstas son herramientas que permiten desde el punto de vista del usuario del servicio medir la calidad del servicio prestado por proveedores de diversas ramas de servicio, incluyendo los bancarios, y conceptualizando a la calidad como la diferencia entre

\footnotetext{
${ }^{2}$ Largas colas, líneas caídas, cajeros automáticos desconectados, centrales telefónicas abarrotadas y poca atención al cliente son ejemplos de una situación que se repite a diario en buena parte de los bancos nacionales, desde que sucedió el colapso financiero en $1994($ Gómez, 2005 $)$.

${ }^{3}$ Datanalisis es una organización venezolana con fines de lucro, desde 1985 satisface necesidades de información del mercado para la toma de decisiones empresariales en las áreas de estudios de mercado, análisis de entorno, económicos y estudios de opinión pública.
} 
percepciones y expectativas. Si bien la calidad ha sido concebida desde la óptica del cliente, su medición no puede ser distinta. Para Cantú (2006), los aspectos intangibles no son fáciles de cuantificar, y las expectativas de los clientes son comúnmente mal interpretadas, lo que no debe ser excusa para no realizar la medición. Según Denton (1991) y Pride y Ferrell (1997), la medición debe ser realizada para que los proveedores del servicio conozcan cómo sus clientes los evalúan y por qué éstos prefieren algunos proveedores de servicio antes que a otros.

Algunos de los modelos de medición de la calidad del servicio de mayor difusión, referenciados por Díaz et al. (2006), Hoffman y Bateson, (2002), Gutiérrez (2001) y Setó (2005), son el modelo de diferencias entre expectativas y percepciones, el modelo de las cinco dimensiones o criterios, el modelo integral de las brechas sobre la calidad del servicio, la escala de Servqual y la escala de Servpref. Uno de los modelos más importantes para medir la calidad del servicio es la escala de Servqual, en la cual se resumen los modelos de diferencias entre percepciones y expectativas y el de las cinco dimensiones de la calidad del servicio; dicha escala se basa en cuestionarios aplicados de manera directa a los usuarios, incorporando aspectos cuantitativos y cualitativos agrupados en cinco dimensiones, lo que da un total de 22 declaraciones que intentan recolectar las expectativas de un excelente servicio y las percepciones sobre las mismas dimensiones de los servicios recibidos. Para Lovelock y Wirtz (2008) y Zeithaml et al. (1993), las medidas de desempeño desde la óptica del cliente ofrecen ventajas. Por esta razón, en la presente investigación se consideró la aplicación de dicho método para la medición de la calidad del servicio personal en las agencias bancarias.

Simultáneo a la definición del marco de referencia, se practicó una revisión de fuentes documentales, que facilitaron la identificación de objetivos, variables del estudio e interpretación de resultados. Para la fecha de la revisión no se encontraron investigaciones que midieran la calidad de los servicios a partir de la escala de Servqual, específicamente en el sector financiero o bancario, a excepción de los estudios realizados para la creación de la escala de Servqual y referenciados por Zeithaml et al. (1993). No obstante, existen abundantes aplicaciones de Servqual en el sector hotelero, educativo, líneas aéreas, restaurantes y servicios municipales. Rebolloso et al. (2004) practicaron un análisis de la ampliación de la Servqual en los servicios universitarios de Almeria; en él se constató una vez más la fiabilidad de la escala con la necesidad de ser ampliada y adaptada al contexto universitario incorporando nuevas dimensiones: superación de expectativas, precios, satisfacción, compromiso y canales de participación. Igualmente, De Salvador (2003) de- 
sarrolló un análisis de dicha escala en los servicios educativos de la Universidad de Coruña, en él concluye que las expectativas y percepciones son planos valorativos diferentes y no relacionadas linealmente, razón por la cual la escala de las expectativas no debería ser eliminada sino integrada como un factor ponderado de las percepciones; algunos ítems deberían ser adaptados para adecuarlos a la problemática y terminología del contexto en estudio, y la eliminación de otros como apariencia del personal cuidada por su poca importancia. Vigil et al. (2004) constataron lo adecuado de Servqual como técnica de evaluación y diagnóstico en hoteles de Varadero, en España, con altos niveles de fiabilidad y confiabilidad, así como el bajo nivel de calidad percibida por los usuarios. Es importante destacar que, según Santomá y Costa (2007), desde 1991 se han desarrollado estudios ${ }^{4}$ sobre la calidad a partir de la escala de Servqual en hoteles y actividades turísticas, los cuales han confirmado los atributos de Servqual en el sector turismo, la han validado y han incorporado nuevos atributos, e incluso ha sido el punto de partida para la propuesta de otras escalas de medición de calidad (HOTELQUAL, LODGSERV, LODGQUAL Y HOLSERV).

Dentro de los estudios sobre la calidad del servicio financiero con la aplicación de instrumentos distintos a Servqual destaca un estudio realizado por Barboza (s.f.) con el objetivo de evaluar la calidad de atención al cliente en el Banco de Venezuela. Entre sus principales conclusiones se enfatiza que la demora en transacciones es determinante para la evaluación realizada por los usuarios, por ser un aspecto que perjudicó la relación cliente-empresa. Igualmente, la inseguridad en los telecajeros ocasiona la limitación de su uso; en cuanto al personal, la presión que ejerce la gerencia en la relación laboral, aunado a la poca motivación de los empleados, hace que estos últimos no se encuentren en condiciones para prestar una óptima atención al cliente; la gerencia tampoco considera las sugerencias del personal, lo cual genera pérdida de interés de los empleados al corregir. Barboza (s.f.) sugiere políticas de motivación e incentivos hacia los empleados para aumentar su productividad, crear un buzón de sugerencias, logrando con ello tomar medidas correctivas a tiempo y mejorar la calidad del servicio. Otro estudio sobre el servicio y la actitud del personal del Grupo Financiero Vital fue desarrollado por Zaragoza (s.f.), quien encontró que las principales quejas de los clientes son la lentitud, la

\footnotetext{
${ }^{4}$ Algunos de estos investigadores los referencia Santomá y Costa (2007): Fick y Ritchie (1991), Knutson et al. (1991), Saleh y Ryan (1991), Getty y Thompson (1994), Lockwood (1994), Falses et al. (1999) y Mei et al. (1999).
} 
mala actitud de los empleados y la indisponibilidad del personal. En orden de importancia lo que los clientes esperan del servicio bancario es: mejor atención, buen trato, amabilidad, respuestas claras, personal presentable y eficiente.

\section{Objetivo general y metodología de la investigación}

Ante lo expuesto es pertinente investigar intencionalmente la calidad de los servicios personales de las instituciones financieras. A partir de la escala de Servqual se pretende medir la calidad de los servicios personales prestados en las agencias de las instituciones financieras del municipio Libertador del estado Mérida, Venezuela, durante el primer semestre del 2008, con el objeto de formular sugerencias que eleven y/o apuntalen dicho atributo.

La presente investigación se enmarca dentro del enfoque cuantitativo de investigación con el procedimiento para la adquisición del conocimiento deductivo-inductivo. Se encuentra inscrita en un nivel de conocimiento científico aprensivo analítico, partiendo del nivel exploratorio, descriptivo, a través de un diseño no experimental transversal. Las unidades de análisis están conformadas por la gerencia de las agencias de las instituciones financieras y usuarios que visitan las mismas. De esta manera, existieron dos poblaciones objetos de estudio: los usuarios de las instituciones financieras y las agencias de dichas instituciones. Para los efectos de la presente investigación, se entiende por agencia al establecimiento en el que la institución financiera presta servicio personalizado. La población de agencias estuvo definida como la totalidad de agencias de instituciones financieras del país, se encuentra listada en el directorio elaborado por SUDEBAN (2007). De dicho directorio se seleccionaron las agencias de instituciones financieras ubicadas en el municipio Libertador del estado Mérida, Venezuela, las mismas conforman un total de 40 agencias pertenecientes a los diferentes subsistemas del sistema financiero venezolano, como la banca universal y comercial. Para la población de usuarios no existe un directorio preestablecido porque, en primer lugar, dicha información es considerada de carácter confidencial por parte de las agencias y, en segundo lugar, las personas que visitan dichas agencias no forman parte del directorio de clientes.

Las muestras correspondientes a ambas poblaciones se seleccionaron haciendo uso de la técnica de muestreo probabilística estratificada, lo que permitió practicar inferencias sobre el comportamiento de la población. El tamaño de ambas muestras se calculó a través del criterio de la Varianza Máxima, con un coeficiente de confianza del $95 \%$ y un error de estimación del $5 \%$ (figura 1). De acuerdo con lo 
anterior, y para una población (N) de 40 agencias, el tamaño corregido de la muestra de agencias de instituciones financieras resultó ser de 19 agencias. En cuanto al tamaño de la muestra de población de usuarios, debido a que el investigador no pudo estudiar la población completa de usuarios, por ser de tamaño e integrantes desconocidos ${ }^{5}$ y con el propósito de generalizar los resultados a la población de usuarios, se seleccionó una muestra de acuerdo con el criterio de la varianza máxima para un muestreo probabilístico y para una población infinita (Hurtado, 2000), la cual arrojó un tamaño de 384 usuarios, ubicados en las 19 agencias bancarias con la finalidad de ser encuestados. Tal ubicación se realizó proporcionalmente según la cantidad de usuarios que en promedio diario son atendidos.

\section{Figura 1}

\section{Cálculo del tamaño de muestras}

$\begin{array}{ll}n=\frac{N^{*} Z_{\alpha / 2}^{2} * p^{*} q}{(N-1)^{*} e^{2}+Z_{\alpha / 2}^{2} * p^{*} q}=36,31 \text { agencias bancarias. } & n=\frac{Z_{\alpha / 2}^{2} * p^{*} q}{e^{2}}=\mathbf{3 8 4} \text { usuarios } \\ n=\frac{n^{\prime}}{1+n^{\prime} / \mathrm{N}}=19 \text { agencias bancarias (tamaño de muestra corregido) } & \end{array}$

Fuente: Tomado de Hernández et al. (2006).

En esta investigación se utilizaron las fuentes secundarias y primarias; para estas últimas se empleó la técnica de la encuesta a través de la aplicación de un cuestionario destinado a recolectar las expectativas de los usuarios y otro para recolectar sus percepciones. Todos los instrumentos fueron sometidos a pruebas de validez y confiabilidad. La evidencia sobre la validez de contenido se obtuvo mediante la opinión de expertos; en ella, cuatro especialistas de diversas áreas relacionadas con el tema de estudio (mercadeo, metodología de la investigación y estadística) expresaron su opinión sobre la medida en la cual las variables de cada objetivo estaban reflejadas y medidas en los ítems de cada instrumento (cuestionario). A partir del juicio emitido por los expertos y el nivel de concordancia entre éstos, se calculó el Coeficiente de Proporción de Rangos (CPR) (Hernández et al. 2006), el que una vez corregido fue de 0.95 , valor superior al considerado por Hernández et al. (2006) como coeficiente de validez y concordancia muy alta (0.80). Posterior al

\footnotetext{
${ }^{5}$ La población de usuarios de las agencias de las instituciones financieras no pudo ser listada por las razones mencionadas, tampoco su tamaño puede ser conocido por razones de confidencialidad de la gerencia de la mayoría de agencias financieras, por lo cual se le considera población infinita.
} 
cálculo del CPR y a la opinión de expertos, se realizaron ajustes y una prueba piloto en sujetos del estudio de características similares a las identificadas en la población, en un tamaño no superior al $10 \%$ de cada muestra. Para valorar la fiabilidad de las escalas de los instrumentos, se utilizó el estadístico Alfa o modelo de consistencia interna de Cronbach, el cual mostró coeficientes superiores a 0.80 en todas las escalas analizadas. Por esta razón se considera que las escalas son fiables (cuadro 1).

Una vez recolectados los datos de las fuentes primarias, éstos se ordenaron para la construcción de matrices mediante programas de computación (SPSS y Microsoft Excel). Después se inició el análisis de la estadística descriptiva e inferencial: métodos paramétricos y no paramétricos, análisis bivariados y mulvariantes. Específicamente, y considerando la variedad de instituciones financieras que operan en la localidad en estudio, bancos universales y comerciales, se practicaron pruebas de independencia a partir del estadístico Chi cuadrado, coeficiente de contingencia y de Phi y V de Cramer, de Somers, de Tau-b de Kendall y Tau-c de Kendall, además de las pruebas de Mann-Whitney con el fin de encontrar vinculaciones entre el tipo de agencia y los niveles de expectativas, percepciones y atributos importantes para los usuarios, así como comparar los niveles medios de perspectivas por tipo de agencia, que permitiera a su vez definir acertadamente sugerencias para cada tipo. También con la finalidad de probar las diferencias entre expectativas y percepciones, y medir la calidad de los servicios, se practicaron pruebas de Wilcoxon y pruebas T. La primera como un método estadístico no paramétrico para muestras dependientes o pruebas repetidas, que contrasta las hipótesis sobre igualdad de medianas de variables ordinales; la segunda como un método paramétrico para muestras relacionadas para contrastar hipótesis de diferencia del valor medio de expectativas y percepciones. 


\section{Cuadro 1}

Estadísticos de fiabilidad por escalas contenidas en los cuestionarios

\begin{tabular}{|c|c|c|c|}
\hline \multirow[b]{2}{*}{$\begin{array}{l}\text { Escalas unidimensionales utilizadas en la } \\
\text { recolección de datos de la investigación }\end{array}$} & \multicolumn{2}{|c|}{ Estadísticos de fiabilidad } & \multirow{2}{*}{$\begin{array}{c}\begin{array}{c}\text { Procesamiento } \\
\text { de casos }\end{array} \\
\text { No. válidos }\end{array}$} \\
\hline & $\begin{array}{c}\text { Alfa de } \\
\text { Cronbach }\end{array}$ & $\begin{array}{c}\text { No. de } \\
\text { elementos }\end{array}$ & \\
\hline $\begin{array}{l}\text { Importancia de los atributos o dimensiones } \\
\text { del servicio }\end{array}$ & 0.866 & 10 & 367 \\
\hline $\begin{array}{l}\text { Expectativas sobre la confiabilidad del } \\
\text { servicio }\end{array}$ & 0.937 & 5 & 369 \\
\hline $\begin{array}{l}\text { Expectativas sobre la responsabilidad del } \\
\text { servicio }\end{array}$ & 0.821 & 4 & 371 \\
\hline Expectativas sobre la seguridad del servicio & 0.846 & 4 & 369 \\
\hline Expectativas sobre la empatía del servicio & 0.858 & 4 & 372 \\
\hline $\begin{array}{l}\text { Expectativas sobre la tangibilidad del } \\
\text { servicio }\end{array}$ & 0.935 & 4 & 373 \\
\hline $\begin{array}{l}\text { Perspectivas sobre la confiabilidad del } \\
\text { servicio }\end{array}$ & 0.868 & 5 & 371 \\
\hline $\begin{array}{l}\text { Perspectivas sobre la responsabilidad del } \\
\text { servicio }\end{array}$ & 0.801 & 4 & 369 \\
\hline Perspectivas sobre la seguridad del servicio & 0.884 & 4 & 377 \\
\hline Perspectivas sobre la empatía del servicio & 0.844 & 4 & 374 \\
\hline $\begin{array}{l}\text { Perspectivas sobre la tangibilidad del } \\
\text { servicio }\end{array}$ & 0.816 & 4 & 376 \\
\hline $\begin{array}{l}\text { Actitud del empleado percibida por el } \\
\text { cliente }\end{array}$ & 0.936 & 6 & 384 \\
\hline
\end{tabular}

Fuente: Elaborado a partir de datos recolectados por el investigador.

\section{Resultados}

A partir de la aplicación de la escala de Servqual, se presentan los resultados obtenidos en las 21 declaraciones $^{6}$, para estudiar las diferencias entre percepciones y expectativas.

\footnotetext{
${ }^{6}$ Para la construcción de los instrumentos de recolección de datos, específicamente en la escala de Servqual, se optó por reducir el número de ítems, como parte de la adaptación de la escala, con la colaboración de distintos expertos. Se eliminó un ítem de la dimensión empatía ("De los empleados no se debe esperar una atención personalizada para con los clientes") del modelo original que no tenía demasiado sentido en el ámbito de los servicios personales bancarios. De esta forma se llegó a los 21 ítems o declaraciones agrupados en las cinco dimensiones propuestas por Zeithaml et al. (1993).
} 
Nivel de expectativas sobre el servicio. Los resultados muestran expectativas muy altas con respecto al servicio, la mayoría de usuarios encuestados se muestra totalmente de acuerdo para todas las declaraciones, a excepción de las declaraciones "Es realista esperar un servicio rápido y ágil de los empleados del banco", "En la agencia no importa si están demasiado ocupados para responder rápidamente a las preguntas de sus clientes" y "Es realista esperar que los empleados del banco busquen lo mejor para los intereses de sus clientes". Dado que la mayoría manifestó estar: Ligeramente en desacuerdo, Moderadamente y Ligeramente de acuerdo, respectivamente, en el cuadro 2 se presenta el valor de la escala que más se repite de encuestados, los valores perdidos corresponden a usuarios que no respondieron; la mediana indica que el $50 \%$ de los encuestados le dieron una calificación igual o mayor al valor que indica dicha mediana (6: totalmente de acuerdo, o 4: ligeramente de acuerdo). Al comparar el nivel de expectativas para los usuarios de la banca universal y comercial se observa que en ambas bancas hay el mismo nivel de expectativas, medido a partir de la moda y la mediana, a excepción de las declaraciones asociadas con la rapidez, donde los usuarios de las agencias de la banca comercial esperan niveles más elevados de dicho atributo (los empleados ágiles y eficientes y que nunca están demasiado ocupados para responder sus preguntas).

Asimismo, se practicaron pruebas de asociación o independencia entre cada una de las declaraciones de expectativas de Servqual (variables medidas a través de la escala de likert, cualitativa ordinal) y el tipo de agencia (variable cualitativa nominal). De esta prueba se concluye que las expectativas del usuario son independientes del tipo de agencia que presta el servicio.

Nivel de percepciones sobre el servicio. Los resultados muestran percepciones bajas en cuanto a las variables asociadas a confiabilidad y responsabilidad, pues la mayoría de usuarios se mostraron ligeramente en desacuerdo con las afirmaciones "Cuando en la agencia le prometieron algo en cierto tiempo, lo cumplieron" y "En la agencia bancaria le prestaron el servicio en el tiempo acordado" y ligeramente de acuerdo con "Recibió un servicio rápido y ágil de los empleados del banco"; éstas son variables vinculadas con la rapidez o los tiempos de respuestas (cuadro 3). Se comparó el nivel de percepciones para los usuarios de la banca universal y comercial; se observó que en ambas bancas los usuarios tienen el mismo nivel de percepciones, medido a partir de la mediana y de la moda, a excepción de las declaraciones asociadas con la rapidez ("Cuando le prometieron algo en cierto tiempo, lo cumplieron", "...le prestaron el servicio en el tiempo acordado", y "Recibió un servicio rápido y ágil de los empleados"), donde los usuarios de la 
banca universal percibieron niveles más bajos. Es así como algunas variables con las cuales se mide la confiabilidad y responsabilidad están asociadas al tipo de agencia que presta el servicio.

Se practicaron pruebas de Mann-Whitney para comprobar que los niveles medios de las percepciones entre los usuarios de las agencias de la banca comercial son iguales a los de la banca universal. A partir de los resultados de esta prueba se infiere, con un $95 \%$ de confianza, que los usuarios de las diferentes agencias poseen en promedio los mismos niveles de percepciones en cuanto al servicio recibido, y que los grupos de usuarios de ambos tipos de agencias proceden de poblaciones con igual nivel de percepciones; con excepción de algunas variables asociadas a la confiabilidad (...le prometieron algo en cierto tiempo, lo cumplieron, ...le prestaron bien el servicio, ...le prestaron el servicio en el tiempo acordado), responsabilidad (Recibió un servicio rápido y ágil de los empleados del banco) y seguridad (Los empleados fueron...amables) donde las percepciones hacia ambos tipos de agencias son diferentes.

A partir de estas pruebas, se afirma que existen diferencias en cuanto al servicio ofrecido por las agencias de la banca comercial y universal en los atributos de confiabilidad, responsabilidad debido a que en la banca comercial dichas percepciones son más elevadas, según la tabla de contingencia construida (cuadro 2).

Comparación de las percepciones y las expectativas sobre el servicio. Continuando el análisis, según la metodología de Zeithaml et al. (1993) se compararon las percepciones y las expectativas del servicio por cada atributo de calidad; a esta diferencia se le denomina puntuación de Servqual. Antes de calcular las puntuaciones promedio por cada atributo, es necesario asegurarse estadísticamente de la existencia o no de la diferencia entre expectativas y percepciones. Para ello, se utilizó una prueba de Wilcoxon, y se comparó la igualdad de medianas de las declaraciones de expectativas y de percepciones del servicio. Se infiere que las percepciones no igualaron a las expectativas del servicio, y la puntuación de Servqual no es igual a cero (0), a excepción de la variable "atención individualizada", en la que existe evidencia de que no hay diferencia entre los valores medios de expectativas y percepciones. 
Cuadro 2

Descriptivos para las expectativas y percepciones de la escala de Servqual por tipo de agencia

\begin{tabular}{|c|c|c|c|c|c|c|c|c|c|c|c|c|c|c|c|c|c|c|c|c|c|c|c|c|c|}
\hline & \multirow{4}{*}{ Confiabilidad } & \multicolumn{12}{|c|}{ Expectativas } & \multicolumn{12}{|c|}{ Percepciones } \\
\hline & & \multirow{2}{*}{\multicolumn{4}{|c|}{ Valores totales: }} & \multirow{2}{*}{\multicolumn{4}{|c|}{ Bancos comerciales }} & \multicolumn{4}{|c|}{ Bancos universales } & \multirow{2}{*}{\multicolumn{7}{|c|}{$\begin{array}{l}\text { Bancos comerciales } \\
\text { Valores: } \\
\end{array}$}} & \multirow{2}{*}{\multicolumn{5}{|c|}{$\begin{array}{l}\text { Bancos universales } \\
\text { Valores: }\end{array}$}} \\
\hline & & & & & & & & & & Valo & ores: & & & & & & & & & & & & & & \\
\hline & & Válidos & Pérdidas & Med & Mo. & Válidos & Pérdidas & Med & Mo. & Válidos & Pérdidas & Med & Mo. & Válidos & Pérdidas & Med & Mo. & Válidos & Pérdidas & Med & Mo & Válidos & Pérdidas & Med & Mo. \\
\hline 1 & $\begin{array}{l}\text { Cuando en la agencia se le promete algo } \\
\text { en cierto tiempo, deberían hacerlo }\end{array}$ & 369 & 15 & 6 & 6 & 30 & 3 & 6 & 6 & 339 & 12 & 6 & 6 & 384 & 0 & 3 & 3 & 33 & 0 & 4 & 4 & 351 & 0 & 3 & 3 \\
\hline 2 & $\begin{array}{l}\text { Cuando los clientes tienen un problema, } \\
\text { en la agencia bancaria deberían mostrar } \\
\text { un sincero interés en solucionarlo }\end{array}$ & 369 & 15 & 6 & 6 & 30 & 3 & 6 & 6 & 339 & 12 & 6 & 6 & 372 & 12 & 6 & 6 & 32 & 1 & 6 & 6 & 340 & 11 & 6 & 6 \\
\hline 3 & $\begin{array}{l}\text { En la agencia bancaria deberían prestar } \\
\text { habitualmente bien el servicio }\end{array}$ & 373 & 11 & 6 & 6 & 30 & 3 & 6 & 6 & 343 & 8 & 6 & 6 & 376 & 8 & 6 & 6 & 32 & 1 & 6 & 6 & 344 & 7 & 6 & 6 \\
\hline 4 & $\begin{array}{l}\text { En la agencia bancaria deberían prestar el } \\
\text { servicio en el tiempo acordado }\end{array}$ & 376 & 8 & 6 & 6 & 30 & 3 & 6 & 6 & 346 & 5 & 6 & 6 & 384 & 0 & 3 & 3 & 33 & 0 & 4 & 4 & 351 & 0 & 3 & 3 \\
\hline \multirow[t]{2}{*}{5} & $\begin{array}{l}\text { En la agencia bancaria deberían mantener } \\
\text { sus registros sin errores }\end{array}$ & 371 & 13 & 6 & 6 & 30 & 3 & 6 & 6 & 341 & 10 & 6 & 6 & 378 & 6 & 6 & 6 & 32 & 1 & 6 & 6 & 346 & 5 & 6 & 6 \\
\hline & Responsabilidad & & & & & & & & & & & & & & & & & & & & & & & & \\
\hline 6 & $\begin{array}{l}\text { Cabría esperar que informen puntualmente } \\
\text { y con sinceridad } \\
\text { acerca de todas las condiciones } \\
\text { del servicio bancario }\end{array}$ & 371 & 13 & 6 & 6 & 30 & 3 & 6 & 6 & 341 & 10 & 6 & 6 & 375 & 9 & 6 & 6 & 30 & 3 & 6 & 6 & 345 & 6 & 6 & 6 \\
\hline 7 & $\begin{array}{l}\text { Es realista esperar un servicio rápido y } \\
\text { ágil de los empleados del banco }\end{array}$ & 380 & 4 & 3 & 3 & 32 & 1 & 5 & 6 & 348 & 3 & 3 & 3 & 384 & 0 & 4 & 4 & 33 & 0 & 5 & 5 & 351 & 0 & 4 & 4 \\
\hline 8 & $\begin{array}{l}\text { Los empleados del banco siempre } \\
\text { tienen que estar dispuestos } \\
\text { a avudar a sus clientes }\end{array}$ & 372 & 12 & 6 & 6 & 30 & 3 & 6 & 6 & 342 & 9 & 6 & 6 & 372 & 12 & 6 & 6 & 32 & 1 & 6 & 6 & 340 & 11 & 6 & 6 \\
\hline \multirow[t]{2}{*}{9} & $\begin{array}{l}\text { En la agencia no importa } \\
\text { si están demasiado ocupados } \\
\text { para responder rápidamente } \\
\text { a las preguntas de sus clientes }\end{array}$ & 381 & 3 & 4 & 5 & 32 & 1 & 5 & 5 & 349 & 2 & 4 & 5 & 372 & 12 & 6 & 6 & 32 & 1 & 6 & 6 & 340 & 11 & 6 & 6 \\
\hline & Seguridad & & & & & & & & & & & & & & & & & & & & & & & & \\
\hline 10 & $\begin{array}{l}\text { Los clientes deberían ser capaces de tener } \\
\text { confianza con los empleados del banco }\end{array}$ & 375 & 9 & 6 & 6 & 30 & 3 & 6 & 6 & 345 & 6 & 6 & 6 & 377 & 7 & 6 & 6 & 31 & 2 & 6 & 6 & 346 & 5 & 6 & 6 \\
\hline 11 & $\begin{array}{l}\text { Los clientes deberían ser capaces } \\
\text { de sentirse seguros en sus transacciones } \\
\text { con los empleados del banco }\end{array}$ & 373 & 11 & 6 & 6 & 30 & 3 & 6 & 6 & 343 & 8 & 6 & 6 & 377 & 7 & 6 & 6 & 31 & 2 & 6 & 6 & 346 & 5 & 6 & 6 \\
\hline 12 & $\begin{array}{l}\text { Los empleados del banco } \\
\text { deberían ser siempre amables }\end{array}$ & 373 & 11 & 6 & 6 & 31 & 2 & 6 & 6 & 342 & 9 & 6 & 6 & 384 & 0 & 5 & 6 & 33 & 0 & 4 & 5 & 351 & 0 & 5 & 6 \\
\hline \multirow[t]{2}{*}{13} & $\begin{array}{l}\text { Los empleados deberían recibir } \\
\text { el apoyo adecuado del banco para } \\
\text { desarrollar bien su trabajo }\end{array}$ & 372 & 12 & 6 & 6 & 30 & 3 & 6 & 6 & 342 & 9 & 6 & 6 & 377 & 7 & 6 & 6 & 31 & 2 & 6 & 6 & 346 & 5 & 6 & 6 \\
\hline & Empatía & & & & & & & & & & & & & & & & & & & & & & & & \\
\hline 14 & $\begin{array}{l}\text { En los bancos se debe esperar una atención } \\
\text { individualizada a cada cliente }\end{array}$ & 376 & 8 & 6 & 6 & 31 & 2 & 5 & 5 & 345 & 6 & 6 & 6 & 382 & 2 & 6 & 6 & 33 & 0 & 6 & 6 & 349 & 2 & 6 & 6 \\
\hline 15 & $\begin{array}{l}\text { Se espera que los empleados del banco } \\
\text { conozcan cuáles son las necesidades } \\
\text { específicas de sus clientes }\end{array}$ & 378 & 6 & 5,5 & 6 & 32 & 1 & 5 & 6 & 346 & 5 & 6 & 6 & 382 & 2 & 6 & 6 & 33 & 0 & 6 & 6 & 349 & 2 & 6 & 6 \\
\hline 16 & $\begin{array}{l}\text { Es realista esperar que los empleados } \\
\text { del banco busquen lo mejor } \\
\text { para los intereses de sus clientes }\end{array}$ & 382 & 2 & 4 & 4 & 33 & 0 & 4 & 4 & 349 & 2 & 4 & 4 & 378 & 6 & 6 & 6 & 32 & 1 & 6 & 6 & 346 & 5 & 6 & 6 \\
\hline \multirow[t]{2}{*}{17} & $\begin{array}{l}\text { Se debe esperar que el banco tenga } \\
\text { horarios flexibles y ydaptados a los } \\
\text { diversos tipos de clientes }\end{array}$ & 374 & 10 & 6 & 6 & 30 & 3 & 6 & 6 & 344 & 7 & 6 & 6 & 376 & 8 & 6 & 6 & 31 & 2 & 6 & 6 & 345 & 6 & 6 & 6 \\
\hline & Tangibilidad & & & & & & & & & & & & & & & & & & & & & & & & \\
\hline 18 & $\begin{array}{l}\text { En el banco deberían tener equipos } \\
\text { y nuevas tecnologías de apariencia } \\
\text { moderna }\end{array}$ & 375 & 9 & 6 & 6 & 30 & 3 & 6 & 6 & 345 & 6 & 6 & 6 & 376 & 8 & 6 & 6 & 31 & 2 & 6 & 6 & 345 & 6 & 6 & 6 \\
\hline 19 & $\begin{array}{l}\text { Las instalaciones físicas } \\
\text { deberían ser col banco } \\
\text { atractivas }\end{array}$ & 373 & 11 & 6 & 6 & 30 & 3 & 6 & 6 & 343 & 8 & 6 & 6 & 381 & 3 & 6 & 6 & 33 & 0 & 6 & 6 & 348 & 3 & 6 & 6 \\
\hline 20 & $\begin{array}{l}\text { Los empleados del banco } \\
\text { deberían tener apariencia pulcra }\end{array}$ & 375 & 9 & 6 & 6 & 30 & 3 & 6 & 6 & 345 & 6 & 6 & 6 & 377 & 7 & 6 & 6 & 32 & 1 & 6 & 6 & 345 & 6 & 6 & 6 \\
\hline 21 & $\begin{array}{l}\text { Los elementos materiales y documentación } \\
\text { relacionada con el servicio que ofrecen } \\
\text { los banco s debería ser visualmente } \\
\text { atractivas y sencillas }\end{array}$ & 375 & 9 & 6 & 6 & 30 & 3 & 6 & 6 & 345 & 6 & 6 & 6 & 376 & 8 & 6 & 6 & 31 & 2 & 5 & 5 & 345 & 6 & 6 & 6 \\
\hline
\end{tabular}

6: Totalmente de acuerdo. 5: Moderadamente de acuerdo. 4: Ligeramente de acuerdo. 3: Ligeramente en desacuerdo. Fuente: Elaborado a partir de datos recolectados por el investigador. 
Una vez evidenciada las diferencias entre ambas puntuaciones, se calcularon las puntuaciones promedio de Servqual, según la metodología de Zeithaml et al. (1993) para comparar los niveles de expectativas y percepciones para cada uno de los usuarios encuestados del servicio y para cada una de las declaraciones establecidas en la escala de Servqual. Gráficamente, en el criterio Confiabilidad y Seguridad los usuarios presentaron expectativas más altas que las percepciones sentidas durante la prestación del servicio, razón por la cual las puntuaciones de Servqual resultaron negativas, los servicios brindados por las agencias en cuanto al criterio confiabilidad y seguridad no alcanzaron las expectativas del usuario (gráfica 1). En ambas dimensiones las agencias presentaron déficit de calidad en el servicio personal. Por el contrario, las dimensiones de responsabilidad, empatía y tangibilidad resultaron con una puntuación positiva, por cuanto las expectativas de los usuarios fueron superadas por las percepciones las cuales resultaron ser en promedio más altas. Aunque para la banca universal las puntuaciones de la confiabilidad fueron más negativas que para la comercial, las demás puntuaciones presentaron tendencias similares a las presentadas de la banca comercial.

\section{Gráfica 1}

\section{Puntuaciones global de Servqual por criterio de calidad en el servicio y por tipo de banca}

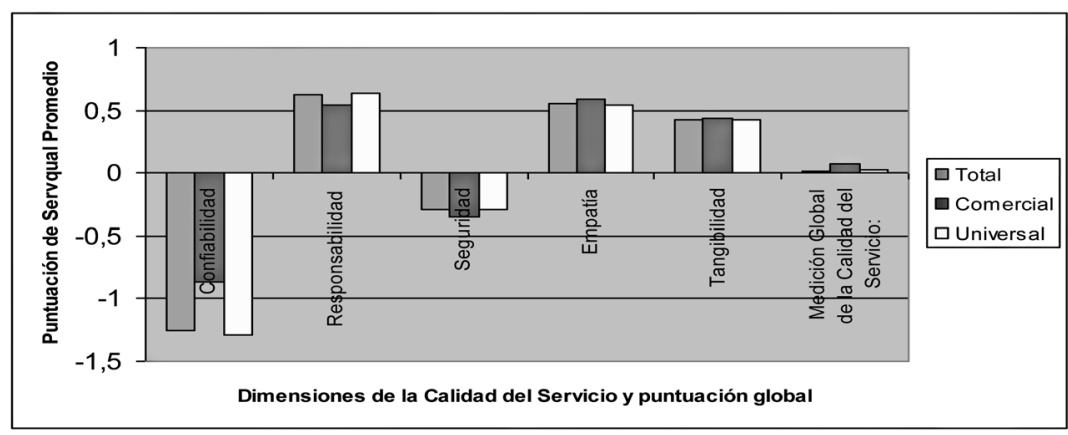

Fuente: Elaborado a partir de datos recolectados por el investigador.

Para analizar las puntuaciones de Servqual con mayor detenimiento, y con la finalidad de inferir cuáles percepciones superan las expectativas, y viceversa, se realizó un contraste del valor promedio de cada una de las 21 declaraciones, conocido como prueba $\mathrm{T}$ para muestras relacionadas o dependientes. Según los resultados se puede inferir, con un $95 \%$ de confianza, que en la totalidad de declaraciones el 
valor promedio de las expectativas es diferente al valor promedio de percepciones del servicio, a excepción de las declaraciones $\mathrm{N}^{\circ} 14$ (atención individualizada) referida a la empatía, donde los promedios son iguales, al igual que lo indicó en la prueba de Wilcoxon. La prueba también informó, a partir del intervalo de confianza construido para la diferencia de medias, que en varias declaraciones las expectativas superan a las percepciones, lo que indicó un déficit de calidad en los servicios, a excepción de algunas declaraciones donde las percepciones superaron las expectativas; estas últimas están asociadas a la responsabilidad $N^{\circ} 7,8$ y 9, a la seguridad $\mathrm{N}^{\circ} 10$ y a la empatía $\mathrm{N}^{\mathrm{o}} 15$ y 16.

\section{Cuadro 3}

\section{Ítems de la escala de Servqual por tipo de agencia}

\begin{tabular}{|c|c|c|c|c|c|}
\hline & & & \multicolumn{2}{|c|}{$\begin{array}{c}\text { Identificación de la } \\
\text { agencia }\end{array}$} & \multirow[b]{2}{*}{ Total } \\
\hline & & & $\begin{array}{c}\text { Banca } \\
\text { comercial }\end{array}$ & $\begin{array}{c}\text { Banca } \\
\text { Universal }\end{array}$ & \\
\hline \multirow{6}{*}{$\begin{array}{l}\text { Recibió un } \\
\text { senvicio rápido } \\
\text { y ágil de los } \\
\text { empleados del } \\
\text { banco }\end{array}$} & Totalmente de ac uerdo & $\begin{array}{l}\text { Recuento } \\
\% \text { del total }\end{array}$ & $\begin{array}{r}6 \\
1,6 \% \\
\end{array}$ & $\begin{array}{r}44 \\
11,5 \%\end{array}$ & $\begin{array}{r}50 \\
13,0 \% \\
\end{array}$ \\
\hline & $\begin{array}{l}\text { Moderadamente de } \\
\text { acuerdo }\end{array}$ & $\begin{array}{l}\text { Recuento } \\
\% \text { del total }\end{array}$ & $\begin{array}{r}14 \\
3,6 \%\end{array}$ & $\begin{array}{r}80 \\
20,8 \%\end{array}$ & $\begin{array}{r}94 \\
24,5 \%\end{array}$ \\
\hline & Ligeramente de acuerdo & $\begin{array}{l}\text { Recuento } \\
\% \text { del total }\end{array}$ & $\begin{array}{r}11 \\
2,9 \% \\
\end{array}$ & $\begin{array}{r}131 \\
34,1 \% \\
\end{array}$ & $\begin{array}{r}142 \\
37,0 \% \\
\end{array}$ \\
\hline & $\begin{array}{l}\text { Ligeramento en } \\
\text { desacuerdo }\end{array}$ & $\begin{array}{l}\text { Recuento } \\
\% \text { del total }\end{array}$ & $\begin{array}{r}0 \\
, 0 \% \\
\end{array}$ & $\begin{array}{r}58 \\
15,1 \% \\
\end{array}$ & $\begin{array}{r}58 \\
15,1 \% \\
\end{array}$ \\
\hline & $\begin{array}{l}\text { Moderadamente en } \\
\text { desacuerdo }\end{array}$ & $\begin{array}{l}\text { Recuento } \\
\% \text { del total }\end{array}$ & $\begin{array}{r}1 \\
, 3 \%\end{array}$ & $\begin{array}{r}20 \\
5,2 \%\end{array}$ & $\begin{array}{r}21 \\
5,5 \%\end{array}$ \\
\hline & $\begin{array}{l}\text { Totalmente en } \\
\text { desacuerdo }\end{array}$ & $\begin{array}{l}\text { Recuento } \\
\% \text { del total }\end{array}$ & $\begin{array}{r}1 \\
, 3 \%\end{array}$ & $\begin{array}{r}18 \\
4,7 \%\end{array}$ & $\begin{array}{r}19 \\
4,9 \%\end{array}$ \\
\hline Total & & $\begin{array}{l}\text { Recuento } \\
\% \text { del total }\end{array}$ & $\begin{array}{r}33 \\
8,6 \% \\
\end{array}$ & $\begin{array}{r}351 \\
91,4 \% \\
\end{array}$ & $\begin{array}{r}384 \\
100,0 \% \\
\end{array}$ \\
\hline \multirow{6}{*}{$\begin{array}{l}\text { Los empleados } \\
\text { del banco } \\
\text { fueron siempre } \\
\text { amables }\end{array}$} & Totalmente de acuerdo & $\begin{array}{l}\text { Recuento } \\
\% \text { del total }\end{array}$ & $\begin{array}{r}5 \\
1,3 \% \\
\end{array}$ & $\begin{array}{r}147 \\
38,3 \% \\
\end{array}$ & $\begin{array}{r}152 \\
39,6 \% \\
\end{array}$ \\
\hline & $\begin{array}{l}\text { Moderadamente de } \\
\text { ac uerdo }\end{array}$ & $\begin{array}{l}\text { Recuento } \\
\% \text { del total }\end{array}$ & $\begin{array}{r}11 \\
2,9 \%\end{array}$ & $\begin{array}{r}111 \\
28,9 \%\end{array}$ & $\begin{array}{r}122 \\
31,8 \%\end{array}$ \\
\hline & Ligeramente de acuerdo & $\begin{array}{l}\text { Recuento } \\
\% \text { del total }\end{array}$ & $\begin{array}{r}11 \\
2,9 \% \\
\end{array}$ & $\begin{array}{r}60 \\
15,6 \% \\
\end{array}$ & $\begin{array}{r}71 \\
18,5 \% \\
\end{array}$ \\
\hline & $\begin{array}{l}\text { Ligeramento en } \\
\text { desacuerdo }\end{array}$ & $\begin{array}{l}\text { Recuento } \\
\% \text { del total }\end{array}$ & $\begin{array}{r}3 \\
, 8 \% \\
\end{array}$ & $\begin{array}{r}26 \\
6,8 \% \\
\end{array}$ & $\begin{array}{r}29 \\
7,6 \% \\
\end{array}$ \\
\hline & $\begin{array}{l}\text { Moderadamente en } \\
\text { desacuerdo }\end{array}$ & $\begin{array}{l}\text { Recuento } \\
\% \text { del total }\end{array}$ & $\begin{array}{r}3 \\
, 8 \% \\
\end{array}$ & $\begin{array}{r}6 \\
1,6 \% \\
\end{array}$ & $\begin{array}{r}9 \\
2,3 \% \\
\end{array}$ \\
\hline & $\begin{array}{l}\text { Totalmente en } \\
\text { desacuerdo }\end{array}$ & $\begin{array}{l}\text { Recuento } \\
\% \text { del total }\end{array}$ & $\begin{array}{r}0 \\
, 0 \% \\
\end{array}$ & $\begin{array}{r}1 \\
, 3 \% \\
\end{array}$ & $\begin{array}{r}1 \\
.3 \% \\
\end{array}$ \\
\hline Total & & $\begin{array}{l}\text { Recuento } \\
\% \text { del total }\end{array}$ & $\begin{array}{r}33 \\
8,6 \% \\
\end{array}$ & $\begin{array}{r}351 \\
91,4 \% \\
\end{array}$ & $\begin{array}{r}384 \\
100,0 \%\end{array}$ \\
\hline
\end{tabular}

Fuente: Elaborado a partir de datos recolectados por el investigador. 
Con la finalidad de hallar dentro de las puntuaciones de Servqual grupos de comportamiento homogéneo o de significado común que permitan determinar la correspondencia o correlación de dichas variables en las instituciones financieras, se practicó un análisis factorial con las puntuaciones de Servqual calculadas para las 21 declaraciones (cuadro 4). A partir de las comunalidades de extracción se determinó que las varianzas de gran parte de las variables resulta expresada por el modelo factorial con la presencia de cinco factores que explican un $81.3 \%$ de la varianza de las puntuaciones de Servqual. Sin embargo, el primer factor de la matriz de componentes agrupa la mayor cantidad de variables dada la cantidad de saturaciones o correlaciones mostradas. Es decir, el primer componente muestra una alta correlación entre la mayor parte de las variables (puntuaciones de Servqual) asociadas a la tangibilidad, seguridad y empatía. El segundo, tercero y quinto componentes muestran una elevada correlación entre variables de la confiabilidad y responsabilidad, asociadas al tiempo de servicio (servicio en el tiempo acordado, rapidez y agilidad y respuestas rápidas a las preguntas), el interés del empleado por los usuarios (sincero interés en solucionar problemas, en ayudar y en buscar lo mejor para las intereses del cliente) y la exactitud del servicio (prestación del servicio sin errores). El cuarto factor está formado por una única variable referida a la amabilidad de los empleados (seguridad), cuya puntuación de Servqual es independiente de las demás.

Factores determinantes de la calidad del servicio. A partir de una revisión documental, se determinó que reconocidos especialistas en el tema piensan que los usuarios no consideran la calidad de los servicios como un concepto de una sola dimensión, sino a través de múltiples factores, identificados por Valarie Zeithaml, A. Parasuraman y Leonard Berry en cinco dimensiones: confiabilidad, responsabilidad, seguridad, empatía y tangibilidad. Estas dimensiones se miden en este estudio según el nivel de importancia otorgada por los usuarios de las agencias bancarias.

Dos atributos fueron utilizados para medir el grado de importancia que el cliente le atribuye a cada una de las cinco dimensiones. Comenzando por la dimensión confiabilidad, la mayoría de usuarios (44.3\%) consideran que el respeto a las instrucciones dadas al personal de atención al cliente son muy importantes; mientras que la importancia de comisiones, cobros y operaciones correctas son también de mucha importancia para un mayor número de encuestados (81.5\%). En cuanto a la responsabilidad: ser atendido de forma rápida y atención rápida a los reclamos, se presenta igualmente como de mucha importancia (55.7\%) para la mayoría de 
los encuestados, especialmente cuando se trata de reclamos (79.7\%). El atributo seguridad se midió a partir de las variables seguridad en las instalaciones y confidencialidad en las operaciones, en su totalidad los usuarios otorgaron elevada importancia. En el atributo empatía, medido a partir de la variable atención amable y respetuosa y adaptado a sus necesidades, el $56.5 \%$ de los encuestados manifestó una elevada importancia al atributo amable y respetuoso; otro porcentaje considerable (31\%) otorgó una importancia de nada a indiferente a este atributo. Sobre la tangibilidad una parte considerable de los encuestados (49\%) consideró la limpieza de las instalaciones como un atributo de mucha importancia al igual que el atributo empleados y espacios físicos agradables (48.2\%). Sin embargo, un porcentaje considerable le otorgó de poca importancia a indiferente a estos atributos, $39.1 \%$ y $38.7 \%$, respectivamente.

El nivel de importancia manifestada por los usuarios a los distintos atributos, se evidencia en el cálculo de la mediana del valor otorgado en una escala del 1 al 5 (cuadro 5). Los atributos con respeto a las instrucciones, limpieza en las instalaciones y aspectos físicos agradables presentaron una mediana inferior al resto de atributos, lo cual indica que la mitad de personas encuestadas le atribuyeron una importancia moderadamente inferior ("importante") que los atributos que presentan una mediana de 5 ("muy importante"). Esta poca e indiferente importancia a la amabilidad, a los espacios físicos limpios y agradables, está asociada a que el usuario asume o espera tácitamente que las instalaciones sean limpias y que los empleados serán agradables y amables, o porque existen otras prioridades como la rapidez y la seguridad; por ejemplo, el que una oficina de atención al cliente esté ordenada no despierta atribuciones positivas ni negativas, pero si existe desorden sí genera insatisfacción. 
Cuadro 4

Análisis factorial de las puntuaciones de Servqual

\begin{tabular}{|c|c|c|c|c|c|c|c|c|c|c|c|c|c|c|}
\hline \multirow{3}{*}{$\begin{array}{c}\text { Análisis factorial } \\
\text { Confiabilidad }\end{array}$} & \multirow{2}{*}{\multicolumn{2}{|c|}{ Comunalidades }} & \multicolumn{7}{|c|}{ Varianza total explicada } & \multirow{2}{*}{\multicolumn{5}{|c|}{ Matriz de componentes(a) }} \\
\hline & & & \multicolumn{4}{|c|}{ Autovalores iniciales } & \multicolumn{3}{|c|}{$\begin{array}{l}\text { Sumas de las saturaciones al } \\
\text { cuadrado de la extracción }\end{array}$} & & & & & \\
\hline & Inicial & Extracción & Componente & Total & $\begin{array}{c}\% \text { de la } \\
\text { varianza }\end{array}$ & $\begin{array}{c}\% \\
\text { acumulado }\end{array}$ & Total & $\begin{array}{c}\text { \% de la } \\
\text { varianza }\end{array}$ & $\begin{array}{c}\% \\
\text { acumulado }\end{array}$ & 1 & 2 & 3 & 4 & 5 \\
\hline $\begin{array}{l}\text { 1.Cuando en la agencia le prometieron algo en cierto tiempo, } \\
\text { lo cumplieron. }\end{array}$ & 1,000 & ,947 & 1 & 9,516 & 45,314 & 45,314 & 9,516 & 45,314 & 45,314 &,- 052 & ,938 &,- 243 &,- 030 &,- 066 \\
\hline $\begin{array}{l}\text { 2. Cuando tuvo un problema, en la agencia bancaria } \\
\text { mostraron un sincero interés en solucionarlo }\end{array}$ & 1,000 & 820 & 2 & 3,016 & 14,360 & 59,675 & 3,016 & 14,360 & 59,675 &, 376 &, 121 &, 223 &,- 195 &, 759 \\
\hline 3. En la agencia bancaria le prestaron bien el servicio & 1,000 & 710 & 3 & 1,891 & 9,007 & 68,681 & 1,891 & 9,007 & 68,681 & 151 &,- 122 & ,798 &,- 110 & 152 \\
\hline $\begin{array}{l}\text { 4. En la agencia bancaria le prestaron } \\
\text { el servicio en el tiempo acordado }\end{array}$ & 1,000 & ,941 & 4 & 1,468 & 6,992 & 75,673 & 1,468 & 6,992 & 75,673 &, 070 & ,936 &,- 232 &,- 023 &,- 067 \\
\hline 5. En la agencia bancaria realizaron sus registros sin errores & 1,000 & 674 & 5 & 1,181 & 5,626 & 81,299 & 1,181 & 5,626 & 81,299 &, 120 &,- 105 & ,798 &, 105 &, 039 \\
\hline \multicolumn{15}{|l|}{ Responsabilidad } \\
\hline $\begin{array}{l}\text { 6. Le informaron puntualmente y con sinceridad acerca de todas las } \\
\text { condiciones del servicio bancario }\end{array}$ & 1,000 &, 752 & 6 &, 842 & 4,011 & 85,309 & & & &, 849 &,- 108 & ,095 & ,093 & 051 \\
\hline 7. Recibió un servicio rápido y ágil de los empleados del banco & 1,000 & 804 & 7 & ,736 & 3,502 & 88,812 & & & & ,256 & ,657 & ,499 & ,064 &,- 233 \\
\hline $\begin{array}{l}\text { 8. Los empleados del banco siempre demostraron } \\
\text { estar dispuestos a ayudar a sus clientes }\end{array}$ & 1,000 &, 758 & 8 &, 490 & 2,333 & 91,145 & & & & ,606 & ,064 &, 139 &,- 075 & ,791 \\
\hline $\begin{array}{l}\text { 9. En la agencia aunque estuvieron demasiado ocupados respondieron } \\
\text { rápidamente a sus preguntas de sus clientes }\end{array}$ & 1,000 & ,908 & 9 &, 406 & 1,933 & 93,077 & & & &, 416 &, 141 & -.115 &, 057 &, 836 \\
\hline \multicolumn{15}{|l|}{ Seguridad } \\
\hline 10. Usted como cliente confió en los empleados del banco & 1,000 & 806 & 10 & 303 & 1,441 & 94,518 & & & & ,716 & ,031 &,- 151 & 520 & 018 \\
\hline $\begin{array}{l}\text { 11. Usted como cliente se sintió seguro } \\
\text { en sus transacciones con los empleados del banco }\end{array}$ & 1,000 & 829 & 11 & 280 & 1,335 & 95,853 & & & &, 844 &,- 002 &,- 320 & 034 &,- 115 \\
\hline 12. Los empleados del banco fueron siempre amables & 1,000 & 248 & 12 & 276 & 1,316 & 97,170 & & & & 262 &, 118 &,- 080 & ,777 &, 062 \\
\hline $\begin{array}{l}\text { 13. Los empleados del banco recibieron el apoyo } \\
\text { adecuado del banco para desarrollar bien su trabajo }\end{array}$ & 1,000 &, 878 & 13 &, 192 & ,915 & 98,085 & & & &, 903 &,- 044 &,- 227 &, 055 &,- 082 \\
\hline \multicolumn{15}{|l|}{ Empatía } \\
\hline 14. Recibió una atención individualizada como cliente & 1,000 & ,900 & 14 &, 122 & ,583 & 98,668 & & & & ,722 & ,009 &,- 169 & 589 & 055 \\
\hline $\begin{array}{l}\text { 15. Los empleados del banco conocieron } \\
\text { sus necesidades específicas como clientes }\end{array}$ & 1,000 & ,763 & 15 &, 094 & ,446 & 99,114 & & & &, 678 &, 021 &,- 115 &, 533 &, 074 \\
\hline $\begin{array}{l}\text { 16. Los empleados del banco buscaron } \\
\text { lo mejor para sus intereses como sus clientes }\end{array}$ & 1,000 & ,883 & 16 & ,082 &, 391 & 99,505 & & & & ,609 &, 864 & ,376 & ,082 &,- 210 \\
\hline $\begin{array}{l}\text { 17. El banco tiene horarios flexibles } \\
\text { y adaptados a los diversos tipos de clientes }\end{array}$ & 1,000 & 897 & 17 & 046 & ,221 & 99,726 & & & &, 846 &,- 042 &,- 114 &,- 385 &,- 137 \\
\hline \multicolumn{15}{|l|}{ Tangibilidad } \\
\hline $\begin{array}{l}\text { 18. En el banco se muestran equipos } \\
\text { y nuevas tecnologías de apariencia moderna }\end{array}$ & 1,000 & ,969 & 18 & 042 & ,201 & 99,927 & & & &, 905 &,- 054 &,- 095 &,- 352 &,- 117 \\
\hline $\begin{array}{l}\text { 19. Las instalaciones físicas del banco son cómodas } \\
\text { y visualmente atractivas }\end{array}$ & 1,000 & ,689 & 19 &, 007 & ,034 & 99,961 & & & &, 736 &,- 310 &,- 050 &,- 182 &,- 120 \\
\hline 20. Los empleados del banco tienen una apariencia pulcra & 1,000 & ,929 & 20 &, 005 & ,026 & 99,987 & & & & ,921 &,- 024 &,- 083 &,- 262 &,- 067 \\
\hline $\begin{array}{l}\text { 21. Los elementos materiales y documentación relacionada con el } \\
\text { servicio que ofrecen los bancos son visualmente atractivos y sencillos }\end{array}$ & 1,000 & ,968 & 21 & ,003 & ,013 & 100,000 & & & & ,924 &,- 052 &,- 101 &,- 300 &,- 107 \\
\hline
\end{tabular}

Método de extracción: Análisis de componentes principales. (a) 5 componentes extraídos

Fuente: Elaborado a partir de datos recolectados por el investigador. 


\section{Cuadro 5}

\section{Estadístico descriptivo de los atributos asociados a la calidad}

\begin{tabular}{|c|c|c|c|c|c|c|c|c|c|c|}
\hline & $\begin{array}{c}\text { Importancia } \\
\text { para el } \\
\text { cliente de } \\
\text { ser } \\
\text { atendido de } \\
\text { forma rápida }\end{array}$ & \begin{tabular}{|} 
Importancia \\
para el \\
cliente \\
de la \\
seguridad \\
en las \\
instalaciones
\end{tabular} & $\begin{array}{c}\text { Importancia } \\
\text { para el cliente } \\
\text { del respeto a } \\
\text { las } \\
\text { indicaciones } \\
\text { o } \\
\text { instrucciones }\end{array}$ & \begin{tabular}{|} 
Importancia \\
para el \\
cliente \\
de la \\
limpieza \\
en las \\
instalaciones
\end{tabular} & $\begin{array}{c}\text { Importancia } \\
\text { para el } \\
\text { cliente } \\
\text { de la } \\
\text { atención } \\
\text { rápida a los } \\
\text { reclamos }\end{array}$ & $\begin{array}{c}\text { Importancia } \\
\text { para el } \\
\text { cliente } \\
\text { de las } \\
\text { comisiones } \\
\text { y cobros } \\
\text { correctos }\end{array}$ & $\begin{array}{c}\text { Importancia } \\
\text { para el } \\
\text { cliente } \\
\text { de la } \\
\text { atención } \\
\text { amable y } \\
\text { respetuosa }\end{array}$ & $\begin{array}{c}\text { Importancia } \\
\text { para el } \\
\text { cliente } \\
\text { que el } \\
\text { servicio } \\
\text { se adpate a } \\
\text { sus } \\
\text { necesidades }\end{array}$ & $\begin{array}{c}\text { Importancia } \\
\text { para el } \\
\text { cliente de } \\
\text { empelados y } \\
\text { espacios } \\
\text { físicos } \\
\text { agradables }\end{array}$ & $\begin{array}{c}\text { Importancia } \\
\text { para el } \\
\text { cliente en la } \\
\text { confidencia- } \\
\text { lidad de sus } \\
\text { operaciones }\end{array}$ \\
\hline $\begin{array}{l}\text { N Válidos } \\
\text { Perdidos } \\
\text { Mediana }\end{array}$ & $\begin{array}{c}369 \\
15 \\
5,00\end{array}$ & $\begin{array}{c}378 \\
6 \\
5,000\end{array}$ & $\begin{array}{c}379 \\
5 \\
4,00\end{array}$ & $\begin{array}{c}381 \\
3 \\
4,00\end{array}$ & $\begin{array}{c}377 \\
7 \\
5,00\end{array}$ & $\begin{array}{c}384 \\
0 \\
5,00\end{array}$ & $\begin{array}{c}384 \\
0 \\
5,00\end{array}$ & $\begin{array}{c}384 \\
0 \\
5,00\end{array}$ & $\begin{array}{c}382 \\
2 \\
4,00\end{array}$ & $\begin{array}{c}382 \\
2 \\
5,00\end{array}$ \\
\hline
\end{tabular}

Fuente: Elaborado a partir de datos recolectados por el investigador.

Al practicarse pruebas estadísticas de asociación entre las variables tipo de agencia y nivel de exigencia en los atributos analizados, se infiere con un $95 \%$ de confianza que los niveles de exigencia establecidos por los usuarios a los atributos dependen del tipo de agencia, que se señalan en los valores críticos del estadístico Chi cuadrado, Coeficiente de contingencia y de Phi y V de Cramer, resultaron ser inferiores a 0.3. Los coeficientes de Somers, de Tau-b de Kendall y Tau-c de Kendall en las pruebas de asociación y dirección entre las variables ordinales: nivel de exigencia en los atributos de calidad y el grado de instrucción de los usuarios mostraron interesantes resultados; sólo algunos tipos de atributos categorizados por niveles de exigencia del cliente: de ser atendido de forma rápida, con respeto a las indicaciones o instrucciones, de limpieza en las instalaciones, la atención amable y respetuosa, que el servicio se adapte a sus necesidades, de instalaciones y empleados agradables, dependen del nivel de instrucción donde a mayor nivel de instrucción corresponde un mayor nivel de exigencia en cuanto a estos atributos. Por el contrario, los coeficientes mencionados evidenciaron independencia entre el nivel de instrucción y las variables: importancia de contar con seguridad en las instalaciones, de que sus reclamos sean atendidos de forma rápida, de que sus operaciones, cobros y comisiones sean correctos y confidencialidad de sus operaciones; es decir, el nivel de exigencia del cliente en cuanto a estos atributos es independiente del nivel de instrucción del usuario; además, todos los usuarios sin importar su nivel de instrucción presentan el mismo nivel de exigencia. 
Factores incontrolables en las expectativas del usuario. Al reflexionar sobre la calidad del servicio concebida como la diferencia existente entre percepciones y expectativas sobre el servicio recibido, y las expectativas de los clientes que se forman, según Zeithaml y Bitner (2002) y Zeithaml, Parasuraman y Berry (1993), por muchos factores incontrolables como experiencias, alternativas del servicio, necesidades personales, comunicaciones del proveedor y otros, se considera que dichos factores intervienen en la calidad del servicio percibida por el usuario al condicionar sus expectativas, por lo que también fueron estudiadas.

Con relación a la variable frecuencia de uso, la mayoría de usuarios (42.4\%) manifestó que visita las agencias bancarias entre 4 y 5 veces por mes, otra porción lo visita menos de tres veces (25\%), mientras que el $20.6 \%$ y $10.2 \%$ realiza una visita mensual que oscila de 6 a 7 veces y de 8 a 9 veces por mes, respectivamente. La cantidad de visitas en promedio para la totalidad de usuarios se ubica en 4.85 visitas por mes; esta cantidad se encuentra dispersa en 2,018 visitas alrededor de esta media. Se infiere con un $95 \%$ de confianza que en las agencias bancarias del municipio Libertador del estado Mérida la cantidad de visitas promedio por usuario se encuentra entre 4.65 y 5.05 visitas.

$\mathrm{Al}$ asociar las variables cantidad de visitas de los clientes con el tipo de agencia, se pudo determinar que la frecuencia de visitas en las agencias bancarias comerciales se encuentra agrupada en un intervalo de visitas menores a 3 y entre 4 y 5 visitas; a diferencia de la frecuencia de visitas en las agencias bancarias universales, donde se encuentran agrupadas en intervalos de frecuencia más elevadas desde menores a 3 hasta llegar a 7 visitas mensuales. Se infiere con un 95\% de confianza que la cantidad promedio de visitas mensuales que realizan los clientes en las agencias bancarias comerciales es levemente superior a los de la banca universal en el municipio Libertador del estado Mérida.

Sobre la variable alternativas del servicio para el usuario, la mayoría de personas manifestó que no tienen otra alternativa para satisfacer sus necesidades de servicios bancarios (34.1\%), puesto que la agencia es la única vía para recibir el tipo de servicio demandado. El hecho de que una buena parte de los usuarios perciba que tiene pocas o ninguna otra alternativa indica que una buena parte de éstos son más tolerantes con el desempeño del servicio, aceptación de horarios menos flexibles o un mayor tiempo de espera, que el usuario que cuenta con otras alternativas (Internet o cajeros automáticos). 
Igualmente, al indagarse sobre las razones por las que el usuario eligió la agencia en particular para recibir el servicio, destaca la razón de ser la única que presta el servicio demandado, aunque ésta no es la de su preferencia. Aun cuando la mayor parte de usuarios encuestados haya manifestado que eligió la agencia porque no tenía más alternativa es importante para las agencias continuar indagando dichas razones, dado que las mismas no son constantes y que estas razones aparte de ser la causa de la elección de la agencia, de alguna forma condicionan las expectativas del servicio, pues constituyen necesidades personales de cada usuario; ejemplo de ello es el hecho de que algunos usuarios hayan elegido la agencia por su rapidez (9.3\%), amabilidad (2.1\%), o facilitad para estacionar (6.0\%). Estos usuarios esperan niveles elevados de comodidad en las instalaciones de la agencia, capacidad de respuesta (rapidez) y seguridad.

\section{Conclusiones, recomendaciones y futuras líneas de investigación}

En cuanto a las expectativas, se encontró que en la mayor parte de ítems asociados a cada una de las dimensiones de la calidad del servicio, los usuarios mostraron niveles elevados. Se presentan bajas percepciones en cuanto a los atributos de confiabilidad y responsabilidad. Se infiere que estos niveles son independientes del tipo de agencia que presta el servicio. Al comparar en promedio las percepciones y las expectativas, esta diferencia se presenta levemente positiva (calidad excelente) en ambos tipos de agencias, a excepción de atributos importantes para el cliente: confiabilidad y seguridad donde existe déficit de calidad en el servicio.

Luego del análisis multivariante practicado, se observó que algunas de las puntuaciones de Servqual que miden importantes aspectos de la confiabilidad (tiempo de servicio) y la seguridad, se encuentran correlacionadas positivamente con aspectos asociados a la responsabilidad, la empatía y la tangibilidad, lo que apunta al seguimiento y fortalecimiento de estos tres últimos aspectos, específicamente del tiempo de servicio, interés del empleado por el usuario y exactitud del servicio, aun cuando en éstos las puntuaciones de Servqual hayan sido positivas o favorables (declaraciones 7, 8, 9 y 16), según la prueba T.

El déficit de la calidad en áreas de tiempo de servicio, posibilidad de errores y seguridad debe ser mejorado por las agencias porque son las áreas en las que los usuarios son más exigentes (respeto a las instrucciones, comisiones, cobros y operaciones correctas, atención rápida, seguridad en las instalaciones y confidencialidad). Asimismo, una gran parte de encuestados manifestó poca importancia a 
la amabilidad, a los espacios físicos limpios y agradables (tangibilidad y empatía), lo que se debió a que normalmente se espera que estos atributos estén presentes en las agencias, y los encuenstados tienen otras prioridades.

Pese a la banca electrónica y otras alternativas del servicio a distancia, se considera que la cantidad de visitas por usuario ( 5 veces al mes) es relativamente alta, lo cual induce a pensar que en Venezuela son muchas las operaciones que no son realizadas a distancia ${ }^{7}$. Esta cantidad de visitas refleja el nivel de exposición que los usuarios experimentan antes de cada visita, moldeando de esta manera los deseos y expectativas del usuario (Zeithaml y Bitner, 2002). Por ello, en las agencias bancarias deben considerarse que la calidad en los servicios depende de las experiencias acumuladas por el usuario, por lo que la calidad debe ser constante y consistente.

A continuación se exponen algunas sugerencias para mejorar la calidad del servicio personal de las agencias bancarias en estudio, especialmente en cuanto a la confiabilidad y seguridad:

Administración de los tiempos de espera, producto de la indurabilidad del servicio. Las agencias bancarias deben atender diariamente personalmente a todos los que asisten, ocasionando una experiencia común para todo el grupo que asiste simultáneamente. Deben manejar la capacidad de la agencia y el nivel de la demanda del servicio para aminorar el efecto adverso de los elevados tiempos de espera. Dado que muchas de las variables en las que los usuarios experimentaron déficit de calidad están asociadas a la rapidez del servicio, en primer lugar, es importante que en las agencias bancarias el nivel de demanda no exceda la capacidad máxima de la agencia, pues es probable que se pierdan oportunidades de negocio con muchos clientes. Asimismo, en caso de recibir el servicio, es posible que la calidad no sea buena por la aglomeración y tiempo de espera a que están sometidos.

Una manera de aumentar la oferta del servicio, y reducir los tiempos de espera, consiste en la reorganización del personal, utilizando una mayor cantidad de personas con entrenamiento cruzado; esto permitirá, por ejemplo, habilitar mayor

\footnotetext{
${ }^{7}$ Apertura de cuentas (ahorros, corrientes y plazos), actualización y cambio de libretas, contratos de tarjetas de crédito y débito, actualización de datos, adquisición de cheques de gerencia, entrega de cheques devueltos, trámites para adquisición de divisas, depósitos, entrega de chequeras, tarjetas extraviadas y de referencias bancarias, reclamos de tarjetas de crédito, débito y cajeros automáticos.
} 
cantidad de cajas o de oficinas de atención al público en momentos de horas pico o días de alta demanda del servicio. También implica la ampliación de equipos, mobiliarios e instalaciones de atención al cliente, puesto que una de las fallas evidenciadas por los usuarios en las agencias es la incomodidad de la espera (falta de sillas y el escaso espacio físico). Otra opción, de menor alcance, es trabajar con mayor rapidez. Un ritmo inapropiado de trabajo, demasiado lento o rápido, es una de las razones más importantes para que el cliente perciba deficiente la calidad en el servicio; se recomienda que el personal de atención al cliente adapte el ritmo de su trabajo para que el mismo no sea tan rápido o lento como para que el cliente perciba que el empleado tiene poco cuidado, poca confiabilidad o de individualización, o perciba que le hacen perder tiempo.

Entre las sugerencias para el manejo de la demanda del servicio destacan la programación de visitas de clientes, éstas pueden ser previstas por segmentos de usuarios: pensionados, ahorristas, deudores y otros; comunicación a los usuarios sobre los horarios y días de mayor afluencia, con esto además de evitar aglomeraciones, los usuarios que esperan por el servicio se sentirán más satisfechos por el simple hecho de haber sido advertidos. Otra opción es modificar la duración y horarios de los servicios, tales como laborar los días de feriado bancario, los cuales en Venezuela podrán ser laborados a discrecionalidad de cada agencia. Otras veces pueden extender sus horarios desde las primeras horas de la mañana, o laborar jornadas especiales durante algunos fines de semana, especialmente en días cuando se tenga previsto alta demanda.

Independientemente de la eficiencia de la gestión de la oferta y la demanda, las fluctuaciones impredecibles de la demanda generan filas de espera; éstas deberán ser administradas para reducir la insatisfacción del usuario. Considerando que las colas son la parte visible de la pérdida de tiempo, si éstas no pueden reducirse significativamente es imprescindible que la espera sea cómoda, agradable y tan corta como se pueda, mediante alguna atención al cliente (bebida, asientos cómodos o lecturas de interés), así la espera será percibida de forma más breve. Otra forma de disminuir la angustia de la espera en el usuario es informándole sobre por qué esperan y cuánto. Adicionalmente, es recomendable que a cada cliente se le establezca un tiempo máximo de espera, lo que puede lograrse con el surtidor automático de números, pues las esperas inciertas son mucho más largas que en las que se conoce el final. En caso de que el tiempo de prestación del servicio no sea cumplido, se deben establecer compensaciones significativas, como recuperación del servicio. 
Recuperación del servicio. Debido a que la existencia de errores son variables de la confiabilidad en el servicio, y a que es imposible asegurar la inexistencia de errores, es importante que las agencias formulen estrategias para recuperar el servicio. Algunas de las formas para reparar el servicio es mediante una indemnización, un bono de consumo o cupones, la exoneración de alguna tarifa, o una nota de crédito en caso de ser cliente del banco; lógicamente dichas prácticas deberán ser estudiadas en el nivel central. Ante las fallas lo menos acertado es una actitud de indiferencia; por el contrario se debe adoptar una actitud activa, y estar preparados para cualquier cosa que pudiera ocurrir: clientes incontrolables o groseros, alteraciones u omisiones en el sistema electrónico, entre otros, y darles a los empleados de atención al cliente un conjunto de herramientas para reparar el servicio en estos casos. En este sentido, el personal de primera línea es el encargado de reaccionar inmediatamente o durante la falla; los usuarios recordarán favorablemente si este personal responde positivamente y no elude o niega el problema. En este caso, el empleado debe aceptar el problema, actuar con amabilidad, receptividad, respeto, disculparse, explicar las razones e inmediatamente proponer las opciones y las compensaciones planificadas según cada tipo de falla.

El primer paso para una respuesta favorable frente a las quejas es incentivarlas, y capacitar a los empleados sobre los mecanismos para resarcir daños, facultarlos para saber cómo actuar y tomar decisiones de emergencia y, sobre todo, para que se interesen por el cliente. El segundo paso es adelantarse a la necesidad de recuperar o reparar el servicio; es importante realizar un seguimiento y análisis de los tipos de falla ocurridas para detectar patrones, frecuencias y fallas frecuentes, lo cual es útil para evitarlas o planificar la reparación. En tercer lugar, se debe responder tan pronto como ocurra la falla, sobretodo cuando los usuarios manifestaron como importante la respuesta breve a los reclamos.

Actitud y desempeño de los empleados. La calidad del servicio radica principalmente en la interacción entre seres humanos, y una de las deficiencias en cuanto a calidad del servicio de las agencias bancarias en estudio se vincula con el desempeño del personal (seguridad). Los empleados no sólo deben dar respuesta al cliente, sino que éste debe sentirse realmente impresionado por el trato y el servicio adicional. Es necesario asegurar que el personal conozca la importancia de su papel, sepa como desempeñarlo y esté facultado para resolver problemas sin ocasionar disgustos a los clientes e incluso proporcionar algo extra (agregar valor). Además, el empleado debe atender siempre con una sonrisa, saludar al cliente si es posible por su nombre y dar las gracias por su visita, de manera sincera, espontánea o natu- 
ral; evitar las distracciones, explicar o informar siempre con amabilidad aunque el cliente no lo sea; controlar los estados de ánimo; sonreír de manera natural y mantener contacto visual al hablar y escuchar; evitar hablar fuerte, agitado o enojado en presencia del cliente. Mantener una actitud de interés hacia todo lo relacionado con el cliente; mostrarle que su interés es satisfacer plenamente sus necesidades y no sólo vender; escuchar y hacer preguntas con interés sobre sus dudas, necesidades, opinión del servicio, a qué le da mayor importancia; debe aprender a detectar y atender las necesidades de los clientes, además de sus necesidades concretas, como son la de ser entendido, bien recibido y de sentirse importante; estar atentos de sus gestos y posturas. Cuidar en todo momento la atención individualizada para no menoscabar la confidencialidad y seguridad del servicio. Manejar información veraz y oportuna sobre regulaciones, normativas y demás políticas vigentes en el nivel del sistema bancario y de la agencia; ello ayudaría a mejorar los niveles de seguridad y responsabilidad percibida por el cliente.

También es importante considerar el estrés provocado por los roles en los empleados de atención al cliente, y más aún si éstos están presionados por largas filas de espera de usuarios impacientes, que en promedio en las agencias estudiadas son iguales a 700 personas diarias. En este caso, es importante que las políticas de personal estén encaminadas al manejo de este tipo de conflictos a través de entrenamientos ante clientes difíciles, mecanismos de motivación, remuneraciones y reconocimientos basados en su desempeño, rotación de cargos, programación de operaciones intermitentes, tiempos de descanso y entrenamiento cruzado.

Considerando la delimitación de la presente investigación, y que las sugerencias formuladas no solucionan totalmente la calidad en los servicios, dada la complejidad del tema, el estudio de la calidad del servicio no se agota. Su análisis, enfoque y aplicabilidad son ilimitados en la búsqueda de la supervivencia y excelencia de los servicios, incluso en otros sectores. Por ello, algunas de las posibles líneas de investigación que surgirán a partir de la presente pueden ser:

- Investigaciones explicativas sobre las causas de las diferencias entre expectativas y percepciones de los usuarios del servicio personal de dichas instituciones.

- Análisis de la calidad de los servicios electrónicos de las instituciones financieras, que involucre medición y diagnósticos de la calidad de estos tipos de servicios.

- Estudio de la calidad de los servicios de las instituciones financieras, a través de otros sistemas de información (encuesta postservicio, encuestas a 
los empleados, compradores encubiertos, informes de quejas y sugerencias del usuario) que consideren otros puntos de vista.

- Estudios de la calidad de los servicios en otros sectores distintos a los de las instituciones financieras: comercios, servicios de salud, transporte y otros.

\section{Referencias}

Barboza, E. (s.f.). Evaluación de la calidad de atención al cliente del banco de Venezuela. Trabajo inédito, Venezuela, Universidad de Yacambú. Extraído el 12 julio de 2007 desde http://www.gestiopolis.com/recursos/documentos/ fulldocs/mar/kaigemac

Berry, L., D. Bennet y C. Brown, (1989). Calidad de servicio. Una ventaja estratégica para instituciones financieras. Madrid: Ediciones Díaz de Santos.

Cantú, H.(2006). Desarrollo de una cultura de calidad. 3a. ed., México: McGraw-Hill.

Cobra, M. (2002). Marketing de servicios: estrategias para turismo, finanzas, salud y comunicación. 2a. ed., Bogotá: McGraw-Hill.

Datanalisis (2004). Calidad de los servicios públicos y privados en Venezuela. Extraído el 23, julio, 2007, de http://www.datanalisis.com/detalle. asp?id=6\&plantilla $=7$

Denton, K.(1991). Calidad en el servicio a los clientes. Madrid: Ediciones Díaz de Santos.

De Salvador, X. (2003). Calidad en servicios educativos: Análisis del instrumento Servqual. Revista Española de Pedagogía. Año LXI, No 224, pp. 77-94.

Díaz, F., J. Álvarez, O. González, V. Jiménez, M. Bethencourt, J. Vera, C. Fernández, C. Clivaz y R. Matos-Wasem. (2006). Política turística: La competitividad y sostenibilidad de los destinos. Valencia: Editorial Tirant Lo Blanch. 
(2005). La banca al alcance de su mano. Revista Dinero. Extraído el 02, noviembre, 2005, de: http://www.dinero.com.ve/118/portada

Gómez, H. (2005a). Bancos en los ojos del comercio. Revista Dinero. $N^{o} 144$. Extraído el 02, noviembre, 2005, de: http://www.dinero.com.ve/144/portada

Grasso, J. (2006). Banca: ganancias en un panorama de mayor regulación. Revista Dinero, No 202 Extraído el 02 de noviembre del 2006, desde: http://www. dinero.com.ve/202/portada/informe32.html

Gray, J. y T. Harvey. (1997). El valor de la calidad en los servicios bancarios. México: Limusa.

Gutiérrez, D. (2001). La medición de la calidad. En Merchior, M. (Dir.), Turismo en Canarias. España: Fundación Formación y Desarrollo Empresarial, pp. 139-154.

Hernández, R., C. Fernández, y P. Baptista. (2006). Metodología de la investigación. 4a. ed., México: McGraw-Hill Interamericana de México.

Hoffman, K y J. Bateson. (2002). Fundamentos de marketing de servicios. Conceptos, estrategias y casos. 2a. ed., México: Internacional Thomson Editores.

Hurtado, J. (2000). Metodología de la investigación holística. Caracas: SYPAL.

Kotler, P. y G. Armstrong. (2003). Fundamentos de Marketing. 6a., México: McGraw-Hill.

Lovelock, C. y J. Wirtz. (2008). Marketing de servicios. México: Pearson Educación.

Pride, W., O.C. Ferrell y G. Lopetegui. (1997). Marketing: conceptos y estrategias. 9a. ed., México: McGraw-Hill.

Rebolloso, E., C. Salvaro, B. Fernández y P. Cantón. (2004). Análisis y ampliación del Servqual en los servicios universitarios. Revista de Psicología del Trabajo y de las Organizaciones. Vol. 20. № 3, 335-373. 
Santomà, R. y G. Costa. (2007). Calidad de servicio en la industria hotelera. Trabajo presentado en la XVI Simposio Internacional de Turismo y Ocio, Esade. Extraído el 12, octubre del 2008, desde: htpp://www.esade.edu/cedit/pdfs/papers/ pdfg.pdf

Setó, D. (2005). La relación entre la calidad de servicio y la fidelidad de servicio. Revista Europea de Dirección y Economía de la Empresa, vol. 14, № 1 , 34-47.

Superintendencia de bancos y otras instituciones financieras - SUDEBAN-. (2007). Listado de oficinas del sector bancario. Extraído el 14, mayo, 2007, de: http://www.sudeban.gob.ve/directorios.php

Vigil, E., W. Valls y A. Romero. (2004). El modelo de Servqual como técnica de evaluación y diagnóstico en empresas hoteleras. Gestión de hoteles y restaurantes. $\mathrm{N}^{\circ} 58,25-29$.

Zaragoza, N. (s.f.). Servicio y actitud del personal del Grupo Financiero Vital. Trabajo inédito, México, Instituto Tecnológico Minatitlán. Extraído el 12 de julio de 2007 desde http://www-gestiopolis.com/recursos2/documentos/ fulldocs/mar/bital.htm

Zeithaml, V. A. Parasuraman y L. Berry. (1993). Calidad total en la gestión de servicios: cómo lograr el equilibrio entre las percepciones y las expectativas de los consumidores. Madrid: Ediciones Díaz de Santos.

Zeithaml, V. y M. Bitner. (2002). Marketing de servicios: un enfoque de integración del cliente a la empresa. 2a. ed., México: Editorial McGraw-Hill. 